\title{
Predicting the pulmonary effects of long-term e-cigarette use: are the clouds clearing?
}

\author{
Lauren C. Davis $\mathbb{C}^{1}$, Elizabeth Sapey $\mathbb{( I D}^{1,2,3}$, David R. Thickett $\mathbb{C}^{1,4}$ and Aaron Scott $\mathbb{C}^{1}$
}

${ }^{1}$ Birmingham Acute Care Research Group, Institute of Inflammation and Ageing, University of Birmingham, Birmingham, UK. ${ }^{2}$ PIONEER, Health Data Research UK (HDRUK) Health Data Research Hub for Acute Care, Birmingham, UK. ${ }^{3}$ Acute Medicine, University Hospitals Birmingham NHS Foundation Trust, Birmingham, UK. ${ }^{4}$ Respiratory Medicine, University Hospitals Birmingham NHS Foundation Trust, Birmingham, UK.

Corresponding author: Aaron Scott (a.scott@bham.ac.uk)

Shareable abstract (@ERSpublications)

Long-term e-cigarette exposure may result in pulmonary inflammation and reduced resistance to respiratory infections, which partially reflects the established effects of cigarette exposure, due to a combination of nicotine exposure and oxidative stress. https://bit.ly/3zwMFE5

Cite this article as: Davis LC, Sapey E, Thickett DR, et al. Predicting the pulmonary effects of longterm e-cigarette use: are the clouds clearing? Eur Respir Rev 2022; 31: 210121 [DOI: 10.1183/ 16000617.0121-2021].
Copyright @The authors 2022

This version is distributed under the terms of the Creative Commons Attribution NonCommercial Licence 4.0. For commercial reproduction rights and permissions contact permissions@ersnet.org

Received: 21 May 2021 Accepted: 16 Sept 2021

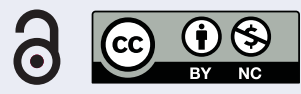

\section{Abstract}

Commercially available since 2007, e-cigarettes are a popular electronic delivery device of ever-growing complexity. Given their increasing use by ex-smokers, smokers and never-smokers, it is important to evaluate evidence of their potential pulmonary effects and predict effects of long-term use, since there has been insufficient time to study a chronic user cohort. It is crucial to evaluate indicators of harm seen in cigarette use, and those potentially unique to e-cigarette exposure. Evaluation must also account for the vast variation in e-cigarette devices (now including at least five generations of devices) and exposure methods used in vivo and in vitro.

Thus far, short-term use cohort studies, combined with in vivo and in vitro models, have been used to probe for the effects of e-cigarette exposure. The effects and mechanisms identified, including dysregulated inflammation and decreased pathogen resistance, show concerning overlaps with the established effects of cigarette smoke exposure. Additionally, research has identified a signature of dysregulated lipid processing, which is unique to e-cigarette exposure.

This review will evaluate the evidence of pulmonary effects of, and driving mechanisms behind, e-cigarette exposure, which have been highlighted in emerging literature, and highlight the gaps in current knowledge. Such a summary allows understanding of the ongoing debate into e-cigarette regulation, as well as prediction and potential mitigation of future problems surrounding e-cigarette use.

\section{Introduction}

Electronic cigarettes (e-cigarettes) are the most popular electronic nicotine delivery system, delivering vapourised e-cigarette liquid (ECL) containing nicotine in a process known as vaping. This alternative to conventional tobacco cigarettes is marketed as a smoking cessation tool. A wick draws ECL to a heated coil and the resultant vapour can then be inhaled. Humectants vegetable glycerin (VG) and propylene glycol (PG) are combined to form the basis of ECL, with additional chemicals frequently added to create flavoured ECL [1].

The value of e-cigarettes for smoking cessation is a complex issue, reviewed elsewhere [2]. Early studies in the general smoking population suggested e-cigarettes did not benefit quit attempts [3]. As yet, no clinical trial has compared e-cigarettes against the current gold standard for smoking cessation, varenicline. However, a recent landmark randomised control trial using e-cigarettes alongside tailored support doubled the quit rate over other nicotine replacement therapies. While representing a significant benefit to smoking cessation, $80 \%$ of those who quit with e-cigarette aid were still using e-cigarette devices after 1 year [4]. The implications of this long-term usage remains unknown. Studies have also highlighted a proportion of 
e-cigarette users (vapers) who continue to use cigarettes. These people are termed dual-users, and represent another group whose use patterns must be taken into account by research [5]. Additionally, in some regions there is a trend for the uptake of e-cigarettes in people who have never smoked, particularly in young people in the USA [6, 7]. Therefore, it is important to evaluate the benefits of e-cigarettes for populations undertaking smoking cessation, against the potential negative consequences of extended exposure in those using e-cigarettes beyond their intended remit.

This review will focus on the pulmonary consequences of exposure, with a particular focus on mechanisms driving changes in inflammation and immunity; the more limited evidence of carcinogenic effects [8] and systemic effects on other organ systems have been summarised elsewhere [9]. Parallels will be drawn with the better described effects of cigarette smoke (CS) exposure.

\section{E-cigarette evolution}

E-cigarette device configuration and ECL constituents vary extensively. E-cigarettes developed from single-use "cig-a-likes" to vape pens, then box-mods, with increasing power output and customisable features (figure 1). These devices traditionally delivered freebase nicotine in low VG ECL ( 50\% VG) [1].

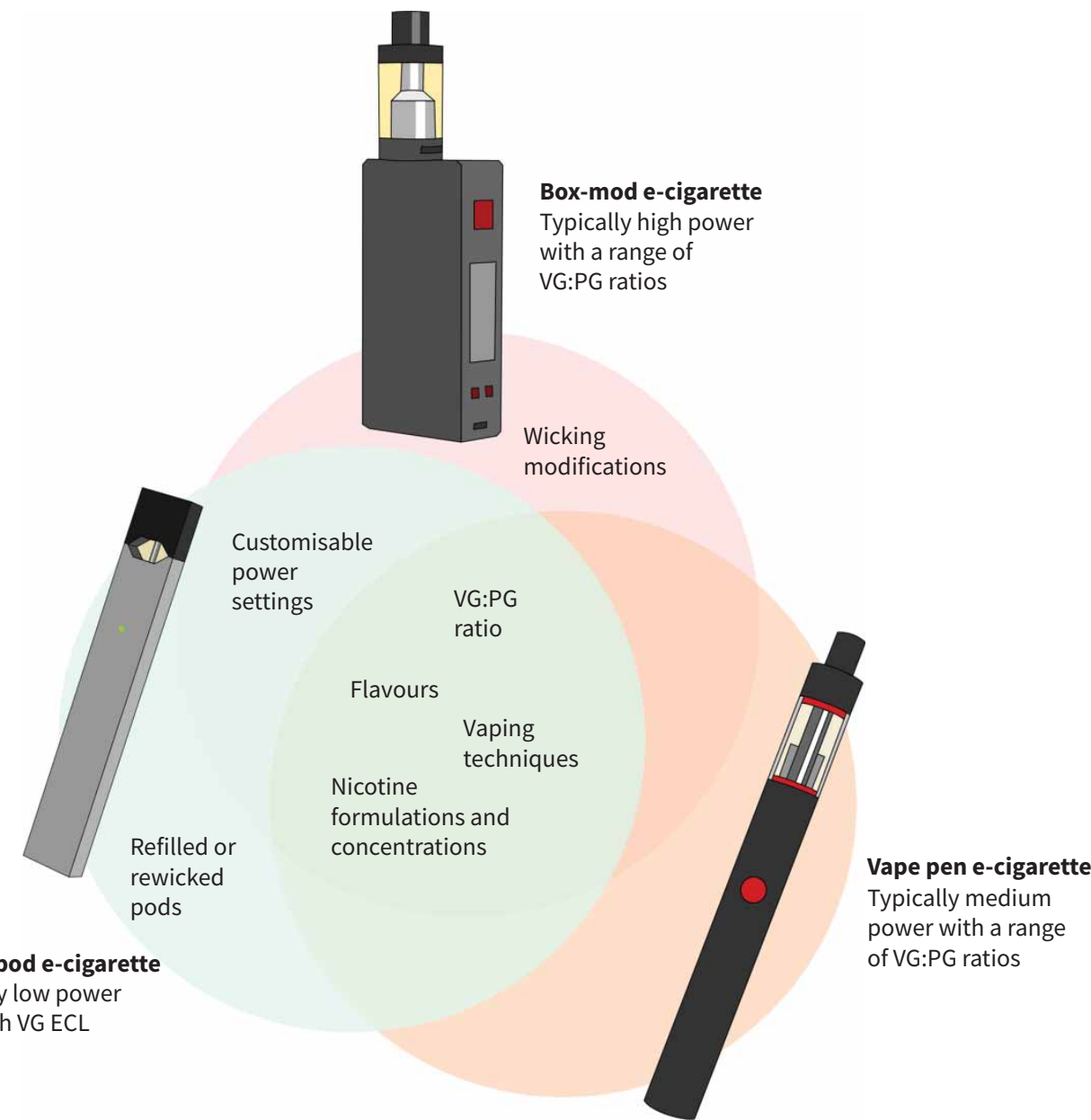

FIGURE 1 Summary of conventional electronic cigarette groups, outlining potential variables between devices. Venn diagram summarising potential variables which contribute to the vapour composition and user exposure during electronic cigarette use. All devices have unique humectant ratios, nicotine content, and formulation and flavouring components, which contribute to composition and exposure, and user technique can alter exposure from all devices. Vape pen and box-mod devices may permit changes in power output, while wicking modifications are limited to large box-mod devices. Closed-pod devices alone can be modified by re-wicking and refilling of pods intended for single use. ECL: e-cigarette liquid; PG: propylene glycol; vG: vegetable glycerin. 
By contrast, the newest generation of closed-pod e-cigarettes deliver nicotine salts in high VG ECL ( 70\% VG) [10]. Closed-pod systems, such as the popular Juul device, require disposable pods containing ECL, and operate at lower power with no customisable features [10]. The popularity of closed-pod devices likely stems from the nicotine formulation. The patent submitted by Juul describes how nicotine salts increase nicotine uptake speed across the alveolar epithelium, producing a rapid spike in blood concentration similar to nicotine uptake from cigarettes [11]. Additionally, protonated nicotine is more palatable, reducing throat-burn associated with freebase nicotine [12], explaining how the higher nicotine concentrations used in Juul devices are tolerated (up to $60 \mathrm{mg} \cdot \mathrm{mL}^{-1}$ in the USA [10]; limited to $20 \mathrm{mg} \cdot \mathrm{mL}^{-1}$ by the EU Tobacco Products Directive [13]).

As the e-cigarette market diversifies, the distinctions between e-cigarette generations have become increasingly blurred (figure 1). For example, nicotine salt ECLs, previously exclusive to closed-pod systems, are now also available for refillable e-cigarettes. Evolving modifications ("mods”) further differentiate newer devices. Devices can be adapted to increase ECL absorption (“wicking”), by dropping ECL directly onto an exposed wick [14-16]. Additionally, some users re-wick and refill disposable pods to customise closed-pod devices [17].

\section{Variation in exposure}

As this field expands, it is important to identify the key variables between devices and liquids that may change vapour composition or the extent of exposure, and thereby contribute to potential harmful effects. Vapour temperature is the most significant variable in determining vapour composition. Several studies have demonstrated that thermal decomposition of humectants and flavourings causes marked changes in the constitution of ECL following vapourisation. Resultant reactive carbonyl species (RCS) [18, 19] are produced at levels which correlate directly with final vapour temperature [20-22]. RCS are implicated in some of the effects of e-cigarette exposure outlined in this review, due to their known biological effects [23], including oxidation of biomolecules causing cytotoxicity, mutagenicity and loss of function, and their significant overlap with RCS known to mediate toxic effects in CS exposure [24-26].

Power input, determined by battery capacity and resistance, directly relates to final temperature and is easily manipulated to user preference. Wick modifications, particularly those that reduce wick saturation, can increase final vapour temperature [27]. ECL composition also determines final temperatures; CHEN et al. demonstrated that the same device produced hotter vapour from PG/VG liquid, than from PG alone [27]. PG:VG ratio must also be mentioned when considering vapour composition, as different ratios could alter the levels of thermal decomposition products in vapour [28, 29].

Chemical additions to ECL also contribute to vapour composition. A comparison of protonated and freebase nicotine in vitro showed differential inflammatory cytokine responses from epithelial cells [30]. It has been suggested that, since protonated nicotine is the ligand for nicotinic receptors, protonated nicotine e-cigarettes may have more inflammatory effects on epithelial cells upon first contact [31]. There is much more work to be done to understand how formulation changes the overall effects of exposure. Fruit, dessert and menthol flavour ECLs add important variation to vapour composition, particularly as some of those in use, such as the butter flavouring diacetyl, have raised concerns due to known risks of inhalation [32].

In addition to altering vapour composition, variables also alter the extent of pulmonary exposure, by changing particulate size and vapour cloud density, thereby changing the permeation and deposition patterns [33]. These variables include temperature, wicking processes and PG:VG ratios. User-specific differences to puff topography will also alter exposure, depending on the number, depth and length of puffs, as well as the method of inhalation [34].

Inevitably, new variables continue to emerge over time. A major challenge in understanding the safety of e-cigarette devices is delineating the universal and unique factors contributing to the toxicity of each device.

\section{Effects of exposure}

Inhaled toxicants can have substantial local and systemic effects, particularly over chronic exposure, as demonstrated by the many effects of cigarette smoking. Epithelial cells are directly exposed to vapour, while adjacent endothelial cells and fibroblasts are indirectly exposed. Additionally, resident alveolar macrophages (AMs) and circulating innate cells, such as neutrophils, are poised to respond to threatening substances or stress. Finally, circulation indirectly exposes multiple organs to inhaled substances and resultant mediators. 
Cigarette smoke and chronic lung disease

Given the partial overlap between the constituents of e-cigarette vapour and CS, the established the effects of chronic CS exposure may inform investigations into effects of chronic e-cigarette use. Comparison of the two serves to further understand the consequences of e-cigarettes for smoking cessation, and the potential negative impacts of dual use.

CS is a complex but well characterised mixture containing nicotine as one of over 5000 compounds [35]. Cigarette smoking is associated with the aetiology of almost every lung disease - lung cancer, asthma, COPD and fibrosis. Chronic CS exposure dysregulates many homeostatic functions, resulting in changes that contribute to lung disease. For example, many lung pathologies are induced by chronic, dysregulated inflammation and exacerbated by subsequent pulmonary infection, which cause gradual loss of lung function.

\section{Progress of current research}

In the current absence of a large cohort of long-term users, it is necessary to extrapolate the effects of chronic vapour exposure from short/medium-term exposure cohorts and acute exposure in vitro experiments. Murine exposure studies also afford the opportunity to examine the impact of medium-term exposure. However, these studies come with their own limitations, including the substantial differences between innate immune responses in mice and humans [36-38].

The variables in e-cigarettes discussed above must be considered when analysing e-cigarette effects in human cohorts versus in vivo and in vitro studies. Furthermore, in vivo and in vitro studies use a wide variety of unstandardised exposure methods. Methods range from direct ECL exposure, e-cigarette vapour extract exposure (EVE), vapour condensate exposure and direct vapour exposure (figure $2 \mathrm{a}-\mathrm{d}$ ).

\section{Inflammation}

Inflammation precedes the clinical manifestation of chronic lung diseases (CLDs). For example, most cases of COPD, a disease frequently associated with chronic smoking, are thought to be driven by dysregulated macrophage activation, followed by recruitment of circulating monocytes, neutrophils and adaptive T-lymphocytes to the airways, with neutrophils in particular implicated with subsequent tissue damage [39]. These changes are accompanied by increased release of the inflammatory cytokines tumour necrosis factor $\alpha$ (TNF $\alpha$ ), interleukin (IL)-6 and IL-8 [40, 41]. With chronic exposure this becomes a self-perpetuating cycle of damaging inflammatory processes within the pulmonary space.

\section{In vivo models}

Murine models employed to study the inflammatory response to long-term e-cigarette exposure have reported varying results. Studies identified no differences in neutrophil, eosinophil and leukocyte count in bronchoalveolar lavage fluid (BAL) from mice exposed over the short (3 days) [42], medium (2-6 weeks) [43-45] and long (4 months) [46] term (table 1). The majority of studies reported no increase in macrophage numbers, although some reported significant increases in BAL [42-47, 50-52] (table 1). Investigation into the adaptive immune cell response is more limited, although increases in CD4+ and CD8+ T-cell counts were reported in one study [45]. Murine models of e-cigarette exposure also show dysregulated cytokine release into airways. The majority of studies reported significantly increased cytokine release, although some reported significant decreases in specific cytokines (table 1). These studies used a range of exposure times, devices and ECLs. Only the study by WANG et al. included a nicotine-free exposure, reporting that cellular recruitment and cytokine release were nicotine dependent. More studies are required to confirm this, particularly as the study delivered 100\% PG ECL. This is not representative of typical ECL, and therefore may omit the effects of mixed humectants and limit the translational value of the nicotine-free results reported.

Exposure regimens, devices and ECL varied between studies. Sussan et al. in particular reported results that contradicted other studies [44], in terms of cellular recruitment and cytokine release. While the regimen was shorter and the device lower powered than the majority of other studies, LERNER et al. reported results in line with other studies using a similar device/liquid and longer exposure time [42] (table 1). This indicates that exposure time and device used are not sufficient to explain these differences.

A range of murine models of CS exposure have demonstrated cellular inflammation (infiltration of

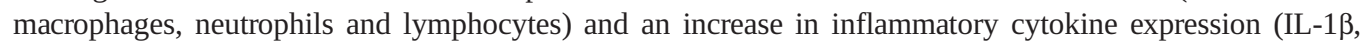
$\mathrm{TNF} \alpha$ ) following as little as 4 days CS exposure [47], with studies extending up to 6 months [48] (table 1). Furthermore, murine models of established CS-driven COPD require between 8 weeks and 6 months of exposure [49]. Given that murine models of e-cigarette treatment that fall within these exposure periods 
d) Direct vapour exposure

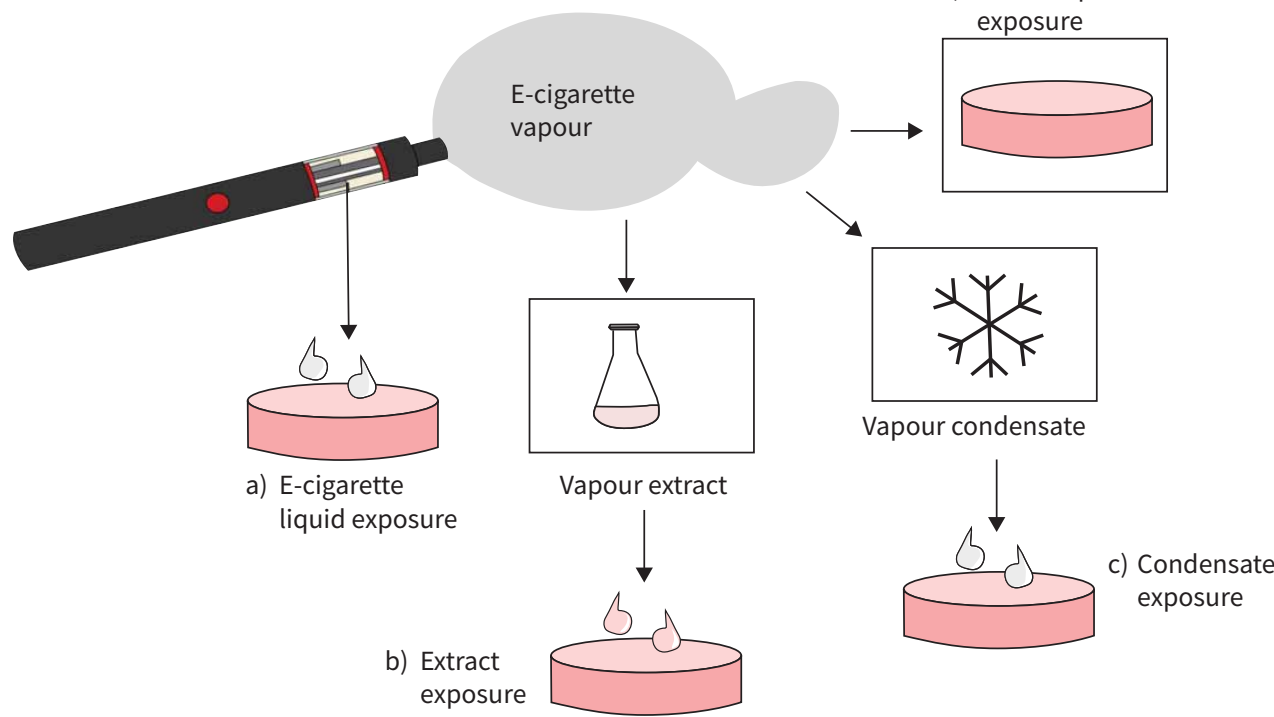

FIGURE 2 Summary of most common e-cigarette exposure systems. a) Direct e-cigarette liquid exposure: e-cigarette liquid is added to culture system without heating. This is a simple screening method; however, it is not representative of the complex chemical changes that occur during thermal decomposition. b) E-cigarette vapour extract exposure: vapour is drawn through culture media for a set period. This culture media is added at a known dilution to the culture system. This method represents thermal decomposition products, but only includes chemicals that dissolve in the media at a given temperature. Chemicals may also cross-react or diminish over time. Finding a physiologically relevant dose of the extract may also be difficult, as this may vary for different constituents of the extract. c) E-cigarette condensate exposure: e-cigarette vapour is cooled by drawing it through tubes at cold temperatures. Condensate can then be added to the culture system. The condensate method also represents thermal decomposition products and does not rely on the products dissolving in media. However, some chemical products may not condense at the apparatus temperature, and chemicals may cross-react or diminish over time. Dosing may also be difficult here with this model. d) Direct e-cigarette exposure: e-cigarette vapour is drawn into a chamber, where it is directly in contact with the culture system. This is the most physiologically relevant model. Puffs are of relevant volume, and contact cells in a similar way as they would in the lungs. Puff regimens can be designed to relate to puff topography studies to give acute or chronic doses. This model is relevant only to cellular exposure in the alveolar space, such as alveolar epithelial cells or alveolar macrophages. Vapour exposure is not an appropriate model for cell types such as endothelial cells or peripheral neutrophils.

detect limited or no immune cell infiltration, it is highly likely that e-cigarette exposure causes reduced immune cell infiltration within the first months of exposure, when compared with CS. Although studies comparing exposures with equivalent nicotine intake have not confirmed that regimens can be directly compared.

Murine studies thus far indicate that e-cigarette exposure causes markedly reduced recruitment of inflammatory cells, when compared with CS exposure. However, they outline a dysregulated inflammatory cytokine response in the airways after relatively short exposure periods (table 1). Although inflammation in CS-exposed mice progresses more quickly, without extensive longitudinal studies, we cannot predict the course inflammation would take with more long-term e-cigarette exposure.

\section{Cohort studies}

There is limited evidence of the inflammatory cell profile in human e-cigarette user cohorts. ReIDEL et al. [53] and Gнosh et al. [54] reported no increase in neutrophil, and neutrophil and macrophage counts respectively, in induced sputum of vapers. The vaper cohorts described in both studies contained mostly ex-smokers, all of whom had been exclusively vaping for at least 6 months. This contrasts with the smoke-naïve mice exposed to e-cigarette vapour for between 3 days and 4 months. Additionally, while murine studies used littermate control groups, exposed to air instead of vapour, human studies have relied 
TABLE 1 Murine studies investigating cytokine and protease levels after e-cigarette exposure. Summary of murine studies investigating

inflammatory cytokine and protease levels in BAL fluid following e-cigarette exposures of varying lengths, in comparison to air exposed control

mice. Representative examples of acute, subacute and chronic murine cigarette smoke exposure models are included for comparison.

\begin{tabular}{|c|c|c|c|c|c|c|c|c|}
\hline \multirow{2}{*}{$\begin{array}{l}\text { Author } \\
\text { [ref.] }\end{array}$} & \multirow[t]{2}{*}{ Year } & \multirow{2}{*}{$\begin{array}{l}\text { E-cigarette } \\
\text { specification }\end{array}$} & \multirow[t]{2}{*}{ ECL details } & \multirow{2}{*}{$\begin{array}{l}\text { Exposure } \\
\text { regime }\end{array}$} & \multirow[t]{2}{*}{ Cells in BAL } & \multicolumn{3}{|c|}{ Cytokines in BAL } \\
\hline & & & & & & Increased & Unchanged & Decreased \\
\hline SUSSAN [44] & 2015 & NJOY vape pen & $18 \mathrm{mg} \cdot \mathrm{mL}^{-1}$ & $\begin{array}{l}1.5 \mathrm{~h} \text { twice } \\
\text { per day, } \\
14 \text { days }\end{array}$ & $\begin{array}{c}\text { No increase in } \\
\text { neutrophil, eosinophil } \\
\text { or lymphocyte count } \\
\text { Increased macrophage } \\
\text { count }\end{array}$ & & MCP-1 & IL-6 \\
\hline LERNER [42] & 2015 & Blu vape pen & $16 \mathrm{mg} \cdot \mathrm{mL}^{-1}$ & $\begin{array}{l}5 \text { h.day }{ }^{-1} \\
3 \text { days }\end{array}$ & $\begin{array}{c}\text { No increase in } \\
\text { macrophage count }\end{array}$ & $\begin{array}{l}\text { IL-6, IL-1 } \alpha \text {, } \\
\text { IL-13, MCP-1 }\end{array}$ & $\begin{array}{l}\text { IL-10, }{ }^{\#} \text { IL-1 } \beta,{ }^{\#} \\
\text { KC, IL-17, } \\
\text { GMCSF, } \\
\text { CXCL10, MIP2 }\end{array}$ & \\
\hline WANG [45] & 2020 & $\begin{array}{l}\text { Joytech } \\
\text { box-mod }\end{array}$ & $\begin{array}{l}25 \mathrm{mg} \cdot \mathrm{mL}^{-1} \\
\left(0 \mathrm{mg} \cdot \mathrm{mL}^{-1}\right. \\
\text { control arm) }\end{array}$ & $\begin{array}{l}2 \mathrm{~h} \cdot \text { day }^{-1} \\
30 \text { days }\end{array}$ & $\begin{array}{c}\text { Increase in } \\
\text { macrophage, CD4 } \\
\text { T-cell and CD8 T-cell } \\
\text { count } \\
\text { No increase in } \\
\text { neutrophil count }\end{array}$ & 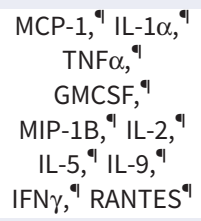 & & \\
\hline Hwang [43] & 2016 & Vape pen & $24 \mathrm{mg} \cdot \mathrm{mL}^{-1}$ & $\begin{array}{l}1 \mathrm{~h} \cdot \text { day }^{-1} \\
28 \text { days }\end{array}$ & $\begin{array}{c}\text { No increase in } \\
\text { macrophage, } \\
\text { neutrophil, eosinophil } \\
\text { or lymphocyte counts }\end{array}$ & KC, IL1r $\alpha$ & & $\begin{array}{l}\text { GMCSF, } \\
\text { IL-3 }\end{array}$ \\
\hline MADISON [46] & 2019 & $\begin{array}{c}\text { Vape pen/ } \\
\text { box-mod }\end{array}$ & $33 \mathrm{mg} \cdot \mathrm{mL}^{-1}$ & $\begin{array}{l}6 \text { min } \cdot \text { day }^{-1} \\
4 \text { months }\end{array}$ & $\begin{array}{l}\text { No increase in } \\
\text { macrophage, } \\
\text { neutrophil or } \\
\text { lymphocyte count } \\
\text { No increase in } \\
\text { dendritic cell or Th17 } \\
\text { cell count }\end{array}$ & $\begin{array}{c}\text { Not } \\
\text { investigated }\end{array}$ & $\begin{array}{c}\text { Not } \\
\text { investigated }\end{array}$ & $\begin{array}{c}\text { Not } \\
\text { investigatec }\end{array}$ \\
\hline VLahos [47] & 2006 & $\begin{array}{l}\text { Commercially } \\
\text { available } \\
\text { filter-tipped } \\
\text { cigarettes }\end{array}$ & & $\begin{array}{c}3,6 \text { or } 9 \\
\text { cigarettes } \\
\text { per day, } 4 \text { days }\end{array}$ & $\begin{array}{l}\text { Dose-dependent } \\
\text { neutrophil increase } \\
\text { Increased } \\
\text { macrophages with } 9 \\
\text { cigarettes per day } \\
\text { No increase in } \\
\text { lymphocyte count }\end{array}$ & $\begin{array}{l}\mathrm{TNF}^{+}{ }^{+}{\mathrm{MIP} 2,{ }^{+}} \\
\mathrm{IL}^{-},{ }^{+} \mathrm{GMCSF}^{+}\end{array}$ & $\mathrm{IL}-10^{+}$ & \\
\hline ВескEтt [50] & 2013 & $\begin{array}{c}\text { 3R4F reference } \\
\text { cigarettes }\end{array}$ & & $\begin{array}{l}\text { Twice per day, } \\
5 \text { times per } \\
\text { week, } \\
\text { 1-12 weeks }\end{array}$ & $\begin{array}{l}\text { Increased macrophage } \\
\text { and neutrophil count } \\
\text { at } 4 \text { days and } 8 \text { weeks } \\
\text { Increased lymphocyte } \\
\text { count at } 8 \text { weeks }\end{array}$ & $\begin{array}{l}\mathrm{TNF}^{+},{ }^{+} \mathrm{IL}-1 \beta{ }^{+} \\
\mathrm{CXCL1}^{+}\end{array}$ & & \\
\hline PhiLLIPS [51] & 2015 & $\begin{array}{l}\text { 3R4F reference } \\
\text { cigarettes }\end{array}$ & & $\begin{array}{l}1 \mathrm{~h} 4 \text { times } \\
\text { per day, } 5 \text { days } \\
\text { per week, } \\
7 \text { months }\end{array}$ & $\begin{array}{c}\text { Increased } \\
\text { macrophage, } \\
\text { neutrophil, } \\
\text { lymphocyte and } \\
\text { dendritic cell count }\end{array}$ & $\begin{array}{l}\text { GMCSF, IFN } \gamma \text {, } \\
\text { IL-1 } \alpha, \text { IL-6, } \\
\text { IP10, MCP1 } \\
\text { TNF } \alpha, \text { MIP1, } \\
\text { MIP2 }\end{array}$ & IL-10, IL-1 $\beta$ & \\
\hline Мотz [52] & 2010 & $\begin{array}{c}\text { 3R4F reference } \\
\text { cigarettes }\end{array}$ & & $\begin{array}{l}4 \text { h } \cdot \text { day }^{-1} \\
5 \text { days per } \\
\text { week, } \\
24 \text { weeks }\end{array}$ & $\begin{array}{c}\text { Increased } \\
\text { macrophage/ } \\
\text { monocyte, neutrophil } \\
\text { and lymphocyte count }\end{array}$ & Not presented & $\begin{array}{c}\text { Not } \\
\text { presented }\end{array}$ & \\
\hline
\end{tabular}

ECL: e-cigarette liquid; BAL: bronchoalveolar lavage; MCP: monocyte chemoattractant protein; IL: interleukin; KC: keratinocyte-derived chemokine; GMCSF: granulocyte-macrophage colony-stimulating factor; CXCL: chemokine (C-X-C motif) ligand; MIP: macrophage inflammatory protein; TNF: tumour necrosis factor; IFN: interferon; RANTES: regulated on activation, normal T-cell expressed and secreted. "\#: Trends suggest increased levels bordering on significance; ": changes dependent on nicotine in $\mathrm{ECL} ;{ }^{+}$: gene expression levels in whole lung tissue. 
on healthy, never-vaper controls, which although relatively well matched, do not account for the previous smoking history of the e-cigarette user cohort.

\section{In vitro evidence}

Epithelial cells and AMs are major contributors of the inflammatory cytokines increased in murine studies. In vitro models of exposure corroborate these increases. Several studies have shown an inflammatory signal in epithelial cells after e-cigarette exposure, reporting increased release of IL-6 [42, 55-58], IL-8 [42, 55, 58, 59] and MCP-1 [55]. Furthermore, Higham et al. demonstrated an increased IL-6 and IL-8 response in e-cigarette-exposed COPD epithelial cells, compared with healthy control cells. This higher propensity to inflammatory output is of particular importance, given that a high proportion of those attempting to quit smoking have COPD [58]. Immune cells also show increased inflammatory mediator output following exposure. AMs exposed to e-cigarette vapour condensate in vitro release increased IL-6, IL-8, TNF $\alpha$ and MCP1 [60]. Recruited cells may further potentiate inflammatory cytokine release following early inflammation, since neutrophils exposed to e-cigarette vapour released significantly more IL-8, in a nicotine-independent manner [61].

Some in vitro studies investigated the mechanism behind inflammatory cytokine output using nicotine-free/ vehicle controls. Wu et al. asserted that increased IL-6 output by epithelial cells was nicotine independent [57], Higham et al. found similar results for IL-8 release by neutrophils [58]. However, other studies highlight that while nicotine-independent mechanisms cause some increased cytokine output by AMs, this effect was greatly exaggerated by nicotine [60]. Additionally, a study on epithelial cell cultures demonstrated that aerosolised nicotine exposure was sufficient to stimulate IL-6, IL-8 and MCP-1 release [55]. This indicates that multiple different inflammatory pathways may be activated by the various constituents of e-cigarette vapour, dependent on cell type, environment and dose (figure 3a).

\section{Proteinase balance}

Proteinases are closely linked to inflammation in lung pathology. In normal homeostasis, antiproteinases hold proteinases in balance until they are deployed for tissue remodelling [62], transmigration and direct antimicrobial action [63, 64]. Tissue damage and loss of function can result from disturbed proteinaseantiproteinase balance [65]. The best characterised proteinases are the serine proteinases, including neutrophil elastase (NE) and proteinase 3 [66], predominantly derived from neutrophils, and matrix metalloproteinases (MMPs), derived from neutrophils, macrophages and the airway epithelium.

Dysregulated proteinase-antiproteinase balance has an established role in the progression of COPD and emphysema. NE release by neutrophils undergoing dysregulated migration through the lung interstitium is directly tied to emphysema progression in COPD [65, 67]. Additionally, MMP-8, -9 and -12 proteinase levels correlate with airflow obstruction and disease progression [68, 69].

A growing body of evidence investigates the effects of e-cigarette exposure on proteinase-antiproteinase balance in the lungs. A human cohort study demonstrated that NE, MMP-2, -8 and -9 levels in BAL were comparable in cigarette smokers and vapers, even in those who never smoked cigarettes [54]. MMP-9 and $\mathrm{NE}$ are also increased in induced sputum from vapers, when compared with never-vaper controls [53].

Murine models also show proteinase dysregulation. After 4 month murine exposure to e-cigarette vapour, MMP-9 and -12 were increased in BAL [55]. Meanwhile, WANG et al. reported a nicotine-independent reduction in MMP-9, and a nicotine-independent increase in MMP-2 and decrease in MMP-8, following exposure to $100 \%$ PG with and without nicotine for 6 weeks [45]. Proteinases are most frequently released by macrophages and neutrophils. Accordingly, previous work by our group [60] has shown an elevated MMP-9 response in AMs after e-cigarette exposure, while others have shown elevated NE and MMP-9 from e-cigarette-challenged neutrophils [61].

Overall, evidence suggests the components of e-cigarette vapour stimulate increased proteinase release into the airways, largely from resident and patrolling immune cells (figure 3a). This signature is reminiscent of various chronic respiratory diseases, highlighting the potential contribution of e-cigarettes to their development and progression. More long-term cohort studies are required to determine the impact of e-cigarette-challenged proteinase released in the lungs.

\section{Inflammatory mechanisms}

Although e-cigarette vapour is vastly simpler than CS, it contains a mixture of nicotine, RCS and additional chemicals such as flavourings. These components contribute to overlapping inflammatory pathways, which potentiate the inflammatory profile widely described in different models of e-cigarette exposure. 
a)
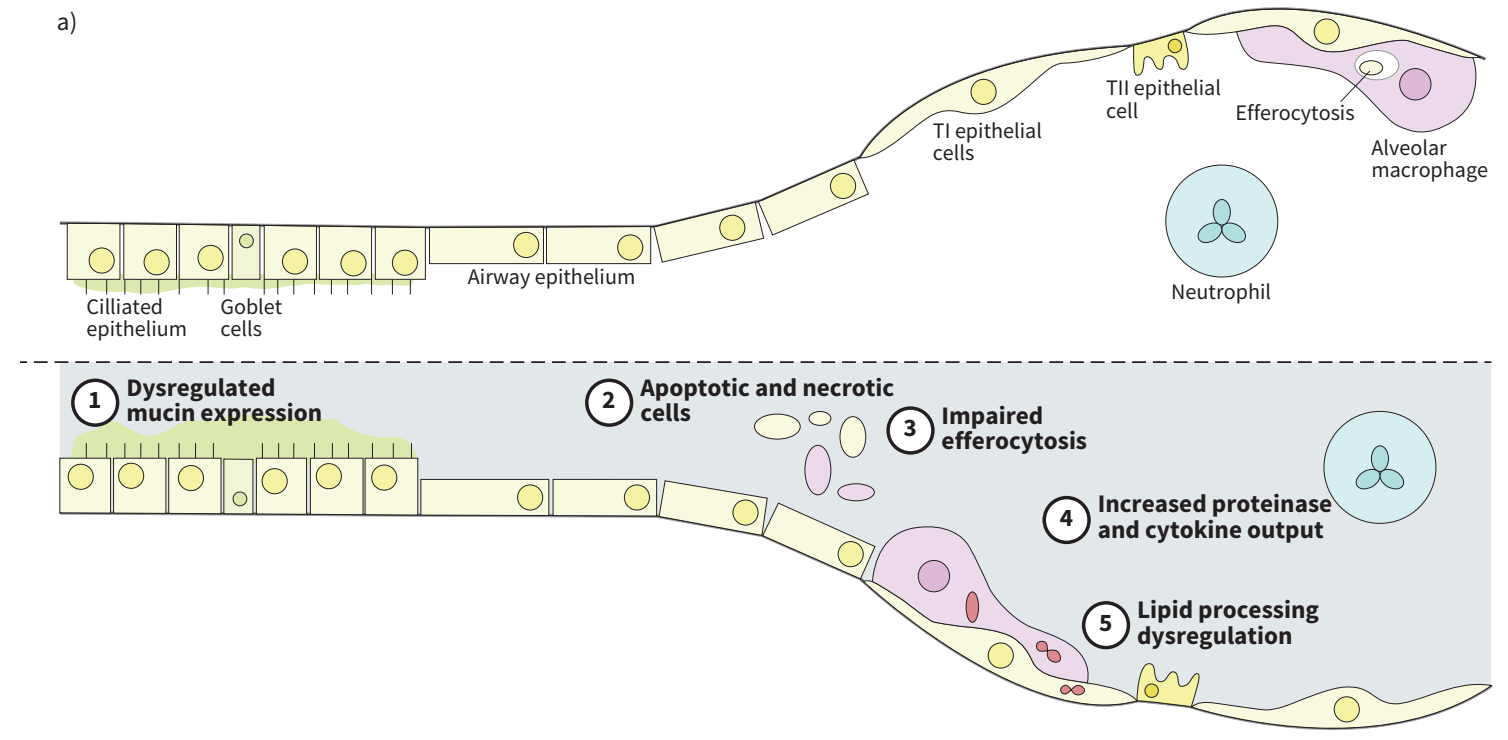

\begin{tabular}{|c|c|c|c|c|}
\hline (1) & (2) & (3) & (4) & (5) \\
\hline $\begin{array}{l}\text { Dysregulated mucin } \\
\text { expression alters } \\
\text { consistency and } \\
\text { velocity }\end{array}$ & $\begin{array}{l}\text { Exposures cause } \\
\text { build-up of apoptotic } \\
\text { and necrotic } \\
\text { epithelial and } \\
\text { immune cells in the } \\
\text { airways }\end{array}$ & $\begin{array}{l}\text { Impaired } \\
\text { efferocytosis by } \\
\text { macrophages } \\
\text { perpetuates } \\
\text { apoptotic cell } \\
\text { build-up }\end{array}$ & $\begin{array}{l}\text { Immune cells and } \\
\text { epithelial cells } \\
\text { release increased } \\
\text { inflammatory } \\
\text { mediators, } \\
\text { including proteases, } \\
\text { reactive oxygen } \\
\text { species and } \\
\text { cytokines }\end{array}$ & $\begin{array}{l}\text { Lipid dysregulation } \\
\text { causes endogenous } \\
\text { lipid inclusions and } \\
\text { impaired lipid } \\
\text { catabolism in } \\
\text { macrophages and } \\
\text { impaired lipid } \\
\text { export in epithelial } \\
\text { cells }\end{array}$ \\
\hline
\end{tabular}
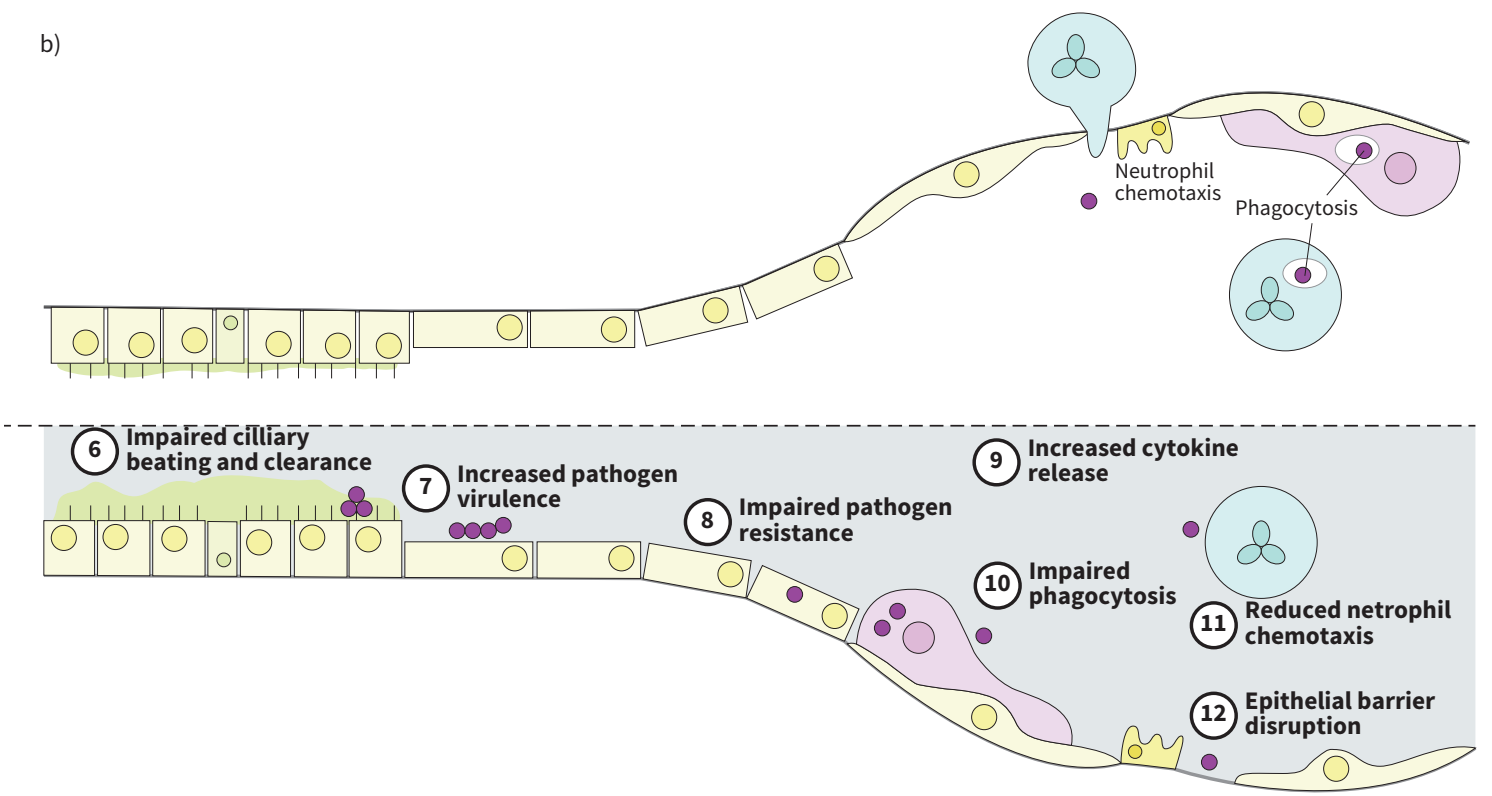

\begin{tabular}{lllll}
\hline \multicolumn{1}{c}{ (6) } & \multicolumn{1}{c}{ (7) } & & (1) &
\end{tabular}

FIGURE 3 Summary of the pulmonary effects of e-cigarettes. Schematic comparison of unexposed (white) and e-cigarette exposed (grey) airways, a) during homeostasis and b) bacterial infection. Tl: type 1 epithelial cells; TII: type 2 epithelial cells. 
Much like CS, a major mediator of the effects of e-cigarette vapour is likely to be oxidative stress. Oxidative stress has been observed in e-cigarette vapour-exposed mice, alongside antioxidant dysregulation with reduced levels of glutathione and oxidised glutathione [42]. In a separate study, mice exposed for 12 weeks showed increased DNA modifications associated with reactive aldehydes [70].

The thermal decomposition of humectants has been demonstrated as a large source of RCS, proportional to the temperature achieved by the vapour [21, 22]. Additionally, it is thought that, in vivo, a small portion of nicotine is metabolised into nitrosamines, whose metabolites include reactive aldehydes and methyldiazohydroxide (MDOH) [71]. Despite debate and variability in the amount of RCS delivered to the lungs, evidence consistently describes RCS at potentially harmful levels. The best characterised of these RCS remain formaldehyde, acetaldehyde and acrolein, which are associated with a variety of pathologies [72].

Following inhalation, RCS react quickly with airway surface liquid components. At low levels they are detoxified [73]. When the detoxification pathways are overwhelmed, unbound RCS cause oxidative stress [23]. In addition to exogenous sources of oxidative stress, we recently demonstrated that AMs exposed to e-cigarettes have an increased capacity to release ROS [60], which may compound oxidative stress locally. RCS permeate into tissue and react with proteins, RNA and DNA, forming adducts [23]. These modifications and RCS-driven mitochondrial respiration [74] can trigger cell death, causing a build-up of apoptotic and necrotic cells in the airways. Protein adducts, and cell components released during necrosis can also act as damage associated molecular patterns (DAMPs), which further potentiate inflammation and the recruitment of inflammatory cells to the lungs [75].

The type of cell death instigated by these processes directs the inflammatory pathways activated within the lungs. SERPA et al. recently demonstrated that e-cigarette aerosol exposure causes a mixture of apoptosis and necrosis in epithelial cells [76]. Necrosis in particular was stimulated in a nicotine-dependent way, although required the presence of other e-cigarette vapour components. Necrosis releases DAMPs responsible for instigating inflammation. Furthermore, e-cigarette exposure causes macrophage apoptosis and necrosis to be increased. Evidence in bone marrow-derived macrophages (BMDMs) demonstrated some macrophages were dying by pyroptosis, an inflammatory programme of cell death often stimulated by intracellular infection [76] leading to further DAMPs release within the lung. Our group demonstrated that viability was partially protected by antioxidant treatment [60], indicating that RCS contribute at least in part to the death of AMs in response to e-cigarette exposure.

The build-up of dead cells, demonstrated by a significant increase in apoptotic cells in murine alveoli following 4 months of e-cigarette exposure [55], may also be potentiated by reduced efferocytosis by sentinel AMs due to a significant reduction in efferocytic capacity in e-cigarette aerosol-exposed BMDMs [76]. This impaired function may be mediated by oxidative damage to cellular machinery. Although the mechanism is yet unexplored in efferocytosis, our group demonstrated that the similar process of phagocytosis, which was also significantly reduced in e-cigarette-exposed AMs, was partially rescued by antioxidant intervention, supporting the role of oxidative stress in this impairment [60].

Nicotine exposure has different effects on each exposed cell type, dependent on nicotine receptor expression. For example, nicotine has been demonstrated to inhibit TNF $\alpha$ expression in human macrophages by binding the $\alpha 7$ subunit of the nAChR receptor [77]. There has been limited investigation of the effect of nAChR engagement following e-cigarette exposure. WANG et al. explored the effects of 6 weeks of e-cigarette exposure on $\mathrm{nAChR} \alpha 7$ knockout mice. This demonstrated that the PG- and nicotine-driven increase of IL-1 $\alpha$, MCP-1 and GM-CSF depended on expression of the receptor, while others including IL-1 $\beta$ and TNF $\alpha$ did not [45]. nAChR $\alpha 7$ knockout prevented NFKB subunit p50 increase following PG and nicotine exposure in female mice [45]. Not only does this indicate that NFkB signalling is activated in part by nicotine exposure in the airways, but it also highlights possible sex differences in murine models which must be taken into account when unpicking potential mechanisms. There is extensive work still required to delineate the nicotinic receptor-driven effects of exposure, with evidence so far beginning to illustrate the complexity of the issue.

Overall, potential mechanisms explored so far emulate the oxidative stress response to CS in healthy smokers and patients with COPD [75] (figure 3a). Further investigation is required to determine the extent of these changes and the receptors, signalling pathways and transcription factors involved in escalating inflammation in e-cigarette-exposed systems. More extensive analysis of NFKB activation would be valuable as, in smoker epithelial cells, NFKB is activated, likely activating inflammatory cytokine secretion [78]. 
Lipid homeostasis

Surfactant permits proper lung function and is maintained by close regulation of lipid and protein components. AMs are largely responsible for homeostatic control of lipids in the lung [79], while type II alveolar epithelial cells produce surfactant proteins [80]. There are several case reports of lipoid pneumonia in vapers [81], with some reports describing lipid-laden macrophages in BAL [82]. The Centers for Disease Control and Prevention and the Food and Drug Administration associated a recent cluster of these cases with vaping tetrahydrocannabinol (THC) and vitamin E acetate (VEA) [83, 84]. Indeed, murine models of VEA vapour exposure demonstrated the development of lipid-laden macrophages [85, 86].

A minority of e-cigarette, or vaping product, use-associated lung injury (EVALI) cases appear to be independent of VEA [81]. Bronchoalveolar lavage fluid (BALF) from a cohort of vapers and smokers indicated significantly more lipid-laden macrophages in both groups than in BALF from never-smokers. BALF from smokers and vapers also contained significantly reduced surfactant A protein [87]. Additionally, a murine model of 4 months of conventional e-cigarette exposure resulted in lipid dysregulation [46]. AMs from exposed mice had endogenous lipid inclusions and disorganised intracellular organelles [46]. Independent of nicotine, exposure-impaired macrophage lipid catabolism and dysregulated lipid export protein expression in alveolar epithelial type II (ATII) cells. Additionally, e-cigarettes decreased surfactant protein production by ATIIs [46] (figure 3a). Given the lipid nature of e-cigarette humectants, it is plausible that VEA may accelerate lipid dysregulation seen following conventional vaping.

Dysregulated lipid homeostasis is a potential effect unique to e-cigarettes, not previously reported in chronic CS studies. Given the emerging evidence from human and murine studies, it is clear that lipid homeostasis requires extensive further investigation in these models, particularly because of evidence implicating lipid metabolism and export defects in the pathogenesis of COPD [88], idiopathic pulmonary fibrosis [89, 90] and several other pulmonary diseases [91].

\section{Infection}

It is widely accepted that CS exposure increases risk of respiratory infections [92-94]. Studies have demonstrated that e-cigarette-exposed mice have increased vulnerability to bacteria and viruses. Two weeks of e-cigarette exposure increased bacterial load in mice infected with Streptococcus pneumoniae, as well as delaying recovery and reducing survival in mice infected with influenza (H1N1) [44]. Three months of exposure also reduced survival against influenza (H2N3) in a nicotine-independent manner [95]. Various mechanisms may contribute to improved pathogen survival in murine models of e-cigarette exposure, as discussed below.

\section{Virulence}

E-cigarette exposure may improve the virulence of some pathogens, increasing their ability to persist in the host. Various bacterial strains were more virulent in a larval model of infection following vapour exposure [95]. Additionally, methicillin-resistant Staphylococcus aureus (MRSA) grown in EVE were more virulent in mice, and more able to form biofilms, invade epithelial cells, persist intracellularly in epithelial cells and resist antimicrobial LL-37 [43].

The mechanism behind these changes in bacterial virulence are unclear. HwANG et al. identified changes in virulence gene expression, such as Coa, which drives $S$. aureus abscess formation [43]. Additionally, e-cigarette-exposed MRSA had altered surface charge [43], similar to changes observed in CS-exposed MRSA [96], which aids immune evasion and biofilm formation. Oxidative stress is a possible stimulus for these changes, since it is a driver of bacterial stress response [96, 97].

\section{Mucociliary clearance}

Many CLDs increase risk of infection by impairing mucociliary clearing, preventing effective pathogen expulsion [98]. Evidence indicates that e-cigarettes dysregulate expression of mucins, which determine mucus consistency. Vapers show increased mucin expression in epithelial cells [99] and induced sputum [53]. Increased mucin expression (MUC5A) was reflected in two murine models of e-cigarette exposure [55, 99]. Additionally, an ovine model of nebulised ECL demonstrated reduced mucus velocity [100]. In vitro, exposed epithelial cells released more viscous mucus [100], had reduced ciliary beating frequency [100] and impaired cystic fibrosis transmembrane conductance regulator (CFTR) conductance, in a nicotine-dependent manner [55]. A study comparing direct vapour exposure of primary nasal epithelial cells from smokers and nonsmokers showed that cells from nonsmokers alone upregulated MUC5A expression, indicating differential effects of exposure in various vaper populations [30]. Cumulatively, evidence indicates that e-cigarette 
exposure disrupts normal mucociliary protection against invading pathogens, potentially escalating to mucostasis or mucus plugging, seen frequently in COPD.

Mucin hypersecretion in COPD is associated with chronic inflammatory signalling, via pathways such as NFк $\beta$ [101]. Similar pathways may be active following e-cigarette exposure; epithelial cell exposure in vitro resulted in protein kinase $\mathrm{C} \alpha(\mathrm{PKC} \alpha)$ and extracellular signal-regulated kinases (ERKs) phosphorylation, downstream of the $\alpha 7 \mathrm{nAChR}$ receptor subunit [55].

\section{Epithelial resistance and barrier function}

Epithelial cells are a major barrier against pathogens, therefore resistance against infection and invasion is crucial. A clinical trial performing nasal inoculation of live-attenuated influenza virus (LAIV) described broad relative downregulation of immune-related gene expression in the nasal epithelium of smokers and vapers [102]. Although not associated with increased viral load, levels of secretory IgA binding LAIV were also reduced in smokers and vapers, suggesting dysregulation of the immune memory developed in these groups.

Epithelial cells exposed to e-cigarette vapour in vitro are more vulnerable to intracellular and extracellular infection by mycobacterium [56] and S. aureus [43] respectively. Wu et al. shared similar findings in human rhinovirus (HRV) viral infection [57]. Furthermore, epithelial barrier function was reduced by acute exposure $\left(<20 \mathrm{~min} \mathrm{day}^{-1}\right.$ for $\leqslant 1$ week) $[59,76]$. SERPA et al. proposed that the drop was due to oxidative stress dependent cellular shedding [76], while CRotTy-AleXAnder et al. showed the effect was exaggerated by bacterial infection [59]. A separate study showed no effect of a single 15 minute e-cigarette exposure on barrier function, while CS exposure containing equivalent nicotine amounts did reduce barrier function [103]. The e-cigarette used in this study was therefore less damaging to epithelial barrier integrity than CS when matched for nicotine delivery.

Cumulatively, studies so far suggest that after e-cigarette exposure, epithelial cells provide abnormally low resistance from invading pathogens, thereby failing at the crucial role of protecting against the constant exposure of the airways.

\section{Immune cell function}

Resident AMs are crucial in the airway response to pathogens, their key functions include cytokine output, migration and phagocytosis. We showed that e-cigarette condensate-exposed human AMs showed impaired phagocytosis of S. aureus and Escherichia coli, which was partially nicotine dependent [60]. Similarly, macrophages from e-cigarette-exposed mice displayed impaired phagocytosis of S. pneumoniae ex vivo, without any change to scavenger receptor expression [44]. Murine BMDMs also demonstrated impaired S. aureus phagocytosis following e-cigarette exposure. This effect was dependent on nicotine, although it could not be replicated with nicotine alone [76]. In vitro macrophage cultures also showed increased intracellular infection [104] (THP1-derived macrophages) and increased bacterial survival [43] (murine AMs).

There are several mechanisms which may contribute to this impaired function, following the extended exposure of AMs to an inflammatory environment at baseline. AMs may become exhausted, rendering them unable to respond to further stimulus; damaged beyond normal function, for example by lipid/DNA peroxidation; and/or supressed by the combination signals within the inflammatory environment. As yet, studies investigating macrophage function have stopped short of dissecting mechanisms behind these changes.

Neutrophils recruitment is crucial for more persistent or numerous respiratory pathogens, with key functions similar to $\mathrm{AMs}$ and a more potent proteinases and anti-bacterial arsenal. Intraperitoneal $P$. aeruginosa, an infection which specifically depends on neutrophil recruitment for clearance, was significantly worsened in mice pre-exposed to e-cigarette vapour for 1 month [105]. This indicates impaired neutrophil recruitment and/or function in these animals. Indeed, human neutrophils exposed to EVE displayed reduced chemotaxis towards $N$-formylmethionyl-leucyl-phenylalanine (fMLP) and phagocytosis of E. coli and S. aureus. Additionally, EVE impaired PMA-driven NETosis (release of neutrophil extracellular traps, containing decondensed chromatin and granule contents) in a nicotine independent way [105].

These effects on innate immune cells are likely to result in increased risk of infection. Impaired macrophage phagocytosis allows the initial outgrowth of pathogens. Further delays in neutrophil recruitment and impaired antimicrobial capacities potentiate this risk. E-cigarette effects on lymphocyte function are as yet unexplored. 
Inflammatory responses

An ordered and proportionate response to pathogenic stimulus is crucial for expulsion of pathogens without persistent inflammation. Several studies demonstrated increased inflammatory cytokine output by e-cigarette-exposed epithelial cells [56, 95] and macrophages [104] in response to bacterial stimulus. Similarly, HRV infection caused IL-6 release from e-cigarette-exposed epithelial cells [57]. It is likely that the long-term inflammation induced by e-cigarette exposure primes the immune response, resulting in a disproportionate response to pathogens. Additionally, impaired immune cell function may result in increased pathogen load or uncontrolled pathogen activity, which would in turn stimulate increased inflammatory responses.

Overall, pathogens with potentially increased virulence are likely to meet disrupted epithelial barriers, protected by impaired mucociliary clearing and patrolled by functionally impaired AMs in the lungs. This is combined with dysregulated cytokine responses, and chemotaxis by secondary responders (figure 3b). There are limited studies into infection rates in cohorts of vapers to support in vivo and in vitro theories; this gap should be filled as risk of respiratory infections needs to be characterised in "healthy" vapers. Beyond this, it is crucial to understand the effects of e-cigarettes on pathogen clearance in patients with COPD using e-cigarettes for smoking cessation, as pathogen-driven acute exacerbations in this group are associated with high mortality rates [106]. Any effects of e-cigarette exposure would therefore have serious repercussions in this context.

\section{Conclusion}

The growing body of evidence surrounding e-cigarette exposure indicates that chronic e-cigarette use will result in changes to the pulmonary environment. In vivo and in vitro models of exposure consistently show dysregulated inflammatory cytokine output, potentially driven by oxidative stress, and disproportionate and ineffective pathogen responses. These changes reflect some elements of the immunopathogenesis of smoking and COPD, although directly comparable studies are limited thus far. Changes to lipid homeostasis also differentiates e-cigarette exposure from cigarette exposure. Chronically, these changes are likely to result in irreversible parenchymal lung tissue damage and impaired gas exchange, contributing to chronic lung conditions in long-term vapers. While effects can largely be attributed to inflammation and/or oxidative stress, the key signalling pathways behind each pathological effect of exposure remain unclear.

\section{Future directions}

Future work should focus on identifying the agent(s) driving pathological mechanisms, and the signalling pathways activated, in order to assess the relative risk of different devices. Alongside continued in vitro studies into chronic exposure, it is imperative we begin long-term longitudinal cohort studies to gain insight into real-world exposure and a clearer picture on the best use of e-cigarettes for cessation. The results of such studies will not be available for some years, therefore a continued combination of in vitro, ex vivo and cohort studies will be required to build a more extensive understanding of the effects e-cigarette exposure and their utility in smoking cessation in the interim. Urgent work is also required to consolidate and communicate our understanding of the harms of e-cigarette uptake in young people who do not smoke.

Provenance: submitted article, peer reviewed.

Conflict of interest: L. Davis reports support for the present manuscript from Wellcome Trust. E. Sapey reports support for the present manuscript from British Lung foundation, MRC, Wellcome Trust, NIHR HTA/EME, and HDR UK. D.R. Thickett reports support for the present manuscript from British Lung foundation, MRC, Wellcome Trust, NIHR HTA/EME, and HDR UK. A. Scott reports support for the present manuscript from British Lung foundation, MRC, Wellcome Trust, NIHR HTA/EME, and HDR UK.

Support statement: supported by the Medical Research Council (grant: MR/L002736/1) and the Wellcome Trust (grant: 2Z0108/Z/30/Z). Funding information for this article has been deposited with the Crossref Funder Registry.

\section{References}

1 Glantz SA, Bareham DW. E-cigarettes: use, effects on smoking, risks, and policy implications. Annu Rev Public Health 2018; 39: 215-235.

2 Worku D, Worku E. A narrative review evaluating the safety and efficacy of e-cigarettes as a newly marketed smoking cessation tool. SAGE Open Med 2019; 7: 2050312119871405.

3 Kalkhoran S, Glantz SA. E-cigarettes and smoking cessation in real-world and clinical settings: a systematic review and meta-analysis. Lancet Respir Med 2016; 4: 116-128. 
Hajek P, Phillips-Waller A, Przulj D, et al. A randomized trial of e-cigarettes versus nicotine-replacement therapy. N Engl J Med 2019; 380: 629-637.

Owusu D, Huang J, Weaver SR, et al. Patterns and trends of dual use of e-cigarettes and cigarettes among U.S. adults, 2015-2018. Prev Med Rep 2019; 16: 101009.

Miech R, Johnston L, O'Malley PM, et al. Trends in adolescent vaping, 2017-2019. N Engl J Med 2019; 381: 1490-1491.

Dutra LM, Glantz SA. High international electronic cigarette use among never smoker adolescents. J Adolesc Health 2014; 55: 595-597.

Bracken-Clarke D, Kapoor D, Baird AM, et al. Vaping and lung cancer - a review of current data and recommendations. Lung Cancer 2021; 153: 11-20.

Eltorai AE, Choi AR, Eltorai AS. Impact of electronic cigarettes on various organ systems. Respir Care 2019; 64: 328-336.

Talih S, Salman R, El-Hage R, et al. Characteristics and toxicant emissions of JUUL electronic cigarettes. Tob Control 2019, 28, 678-680.

Bowen A, Xing C. Nicotine salt formulations for aerosol devices and methods thereof. US20090151717A1. 2015. https://patents.google.com/patent/US20090151717A1/en\#patentCitations

Duell AK, Pankow JF, Peyton DH. Free-base nicotine determination in electronic cigarette liquids by 1 H NMR spectroscopy. Chem Res Toxicol 2018; 31: 431-434.

European Union. Directive 2014/40/EU of the European Parliament and of the Council of 3 April 2014 on the approximation of the laws, regulations and administrative provisions of the Member States concerning the manufacture, presentation and sale of tobacco and related products and repealing Directive 2001/37/EC Text with EEA relevance. OJL 2014; 127: 1-38.

Harrell PT, Eissenberg T. Automated dripping devices for vapers: RDTAs, bottomfeeders, squonk mods and dripboxes. Tob Control 2018; 27: 480-482.

Kong G, Morean ME, Bold KW, et al. Dripping and vape tricks: alternative e-cigarette use behaviors among adolescents. Addict Behav 2020; 107: 106394.

Choi H, Lin Y, Race E, et al. Electronic cigarettes and alternative methods of vaping. Ann Am Thorac Soc 2021; 18: 191-199.

Guy MC, Helt J, Palafox S, et al. Orthodox and unorthodox uses of electronic cigarettes: a surveillance of YouTube video content. Nicotine Tob Res 2019; 21: 1378-1384.

Bekki K, Uchiyama S, Ohta K, et al. Carbonyl compounds generated from electronic cigarettes. Int J Environ Res Public Health 2014; 11: 11192-11200.

Jensen RP, Strongin RM, Peyton DH. Solvent chemistry in the electronic cigarette reaction vessel. Sci Rep 2017; 7: 42549.

Geiss O, Bianchi I, Barrero-Moreno J. Correlation of volatile carbonyl yields emitted by e-cigarettes with the temperature of the heating coil and the perceived sensorial quality of the generated vapours. Int J Hyg Environ Health 2016; 219: 268-277.

Uchiyama S, Noguchi M, Sato A, et al. Determination of thermal decomposition products generated from e-cigarettes. Chem Res Toxicol 2020; 33: 576-583.

Gillman IG, Kistler KA, Stewart EW, et al. Effect of variable power levels on the yield of total aerosol mass and formation of aldehydes in e-cigarette aerosols. Regul Toxicol Pharmacol 2016; 75: 58-65.

Semchyshyn HM. Reactive carbonyl species in vivo: generation and dual biological effects. ScientificWorldJournal 2014; 2014: 417842.

DeJarnett N, Conklin DJ, Riggs DW, et al. Acrolein exposure is associated with increased cardiovascular disease risk. J Am Heart Assoc 2014; 3, e000934.

Torres-Ramos YD, García-Guillen ML, Olivares-Corichi IM, et al. Correlation of plasma protein carbonyls and C-reactive protein with GOLD stage progression in COPD patients. Open Respir Med J 2009; 3: 61-66.

Hecht SS. Cigarette smoking: cancer risks, carcinogens, and mechanisms. Langenbecks Arch Surg 2006; 391: 603-613.

Chen W, Wang P, Ito K, et al. Measurement of heating coil temperature for e-cigarettes with a "top-coil" clearomizer. PLOS ONE 2018; 13: e0195925.

Ooi BG, Dutta D, Kazipeta K, et al. Influence of the e-cigarette emission profile by the ratio of glycerol to propylene glycol in e-liquid composition. ACS Omega 2019; 4: 13338-13348.

Haddad C, Salman R, El-Hellani A, et al. Reactive oxygen species emissions from supra- and sub-ohm electronic cigarettes. J Anal Toxicol 2019; 43: 45-50.

Escobar Y-NH, Morrison $\mathrm{CB}$, Chen Y, et al. Differential responses to e-cig generated aerosols from humectants and different forms of nicotine in epithelial cells from non-smokers and smokers. Am J Physiol Lung Cell Mol Physiol 2021; 320: L1064-L1073.

Shao XM, Friedman TC. Pod-mod vs. conventional e-cigarettes: nicotine chemistry. pH, and health effects. J Appl Physiol 2019; 128: 1056-1058. 
Klager S, Vallarino J, MacNaughton P, et al. Flavoring chemicals and aldehydes in e-cigarette emissions. Environ Sci Technol 2017; 51: 10806-10813.

Sosnowski TR, Odziomek M. Particle size dynamics: toward a better understanding of electronic cigarette aerosol interactions with the respiratory system. Front Physiol 2018; 9: 853.

DeVito EE, Krishnan-Sarin S. E-cigarettes: impact of e-liquid components and device characteristics on nicotine exposure. Curr Neuropharmacol 2018; 16: 438-459.

Centers for Disease Control and Prevention (US); National Center for Chronic Disease Prevention and Health Promotion (US); Office on Smoking and Health (US). How tobacco smoke causes disease: the biology and behavioral basis for smoking-attributable disease: a report of the Surgeon General. Atlanta, Centers for Disease Control and Prevention (US), 2010.

Dawkins PA. Animal models of chronic obstructive pulmonary disease. Thorax 2001; 56: 972-977.

Mestas J, Hughes CCW. Of mice and not men: differences between mouse and human immunology. J Immunol 2004; 172: 2731-2738.

Pulendran B, Davis MM. The science and medicine of human immunology. Science 2020; 369: eaay4014.

Sapey E, Stockley JA, Greenwood H, et al. Behavioral and structural differences in migrating peripheral neutrophils from patients with chronic obstructive pulmonary disease. Am J Respir Crit Care Med 2011; 183: 1176-1186.

Caramori G, Casolari P, Barczyk A, et al. COPD immunopathology. Semin Immunopathol 2016; 38: 497-515.

Barnes PJ. Inflammatory mechanisms in patients with chronic obstructive pulmonary disease. $J$ Allergy Clin Immunol 2016; 138: 16-27.

Lerner CA, Sundar IK, Yao H, et al. Vapors produced by electronic cigarettes and e-juices with flavorings induce toxicity, oxidative stress, and inflammatory response in lung epithelial cells and in mouse lung. PLOS ONE 2015; 10: e0116732.

Hwang JH, Lyes M, Sladewski K, et al. Electronic cigarette inhalation alters innate immunity and airway cytokines while increasing the virulence of colonizing bacteria. J Mol Med 2016; 94: 667-679.

Sussan TE, Gajghate S, Thimmulappa RK, et al. Exposure to electronic cigarettes impairs pulmonary anti-bacterial and anti-viral defenses in a mouse model. PLOS ONE 2015; 10: e0116861.

Wang Q, Sundar IK, Li D, et al. E-cigarette-induced pulmonary inflammation and dysregulated repair are mediated by $\mathrm{nAChR} \alpha 7$ receptor: role of $\mathrm{nAChR} \alpha 7$ in SARS-CoV-2 Covid-19 ACE2 receptor regulation. Respir Res 2020; 21: 154.

Madison MC, Landers CT, Gu B-H, et al. Electronic cigarettes disrupt lung lipid homeostasis and innate immunity independent of nicotine. J Clin Invest 2019; 129: 4290-4304.

Vlahos R, Bozinovski S, Jones JE, et al. Differential protease, innate immunity, and NF-kappaB induction profiles during lung inflammation induced by subchronic cigarette smoke exposure in mice. Am J Physiol Lung Cell Mol Physiol 2006; 290: L931-L945.

Vlahos R, Bozinovski S. Recent advances in pre-clinical mouse models of COPD. Clin Sci 2014; 126: 253-265. Jones B, Donovan C, Liu G, et al. Animal models of COPD: what do they tell us? Respirology 2017; 22: 21-32. Beckett EL, Stevens RL, Jarnicki AG, et al. A new short-term mouse model of chronic obstructive pulmonary disease identifies a role for mast cell tryptase in pathogenesis. J Allergy Clin Immunol 2013; 131: 752-762.

Phillips B, Veljkovic E, Peck MJ, et al. A 7-month cigarette smoke inhalation study in C57BL/6 mice demonstrates reduced lung inflammation and emphysema following smoking cessation or aerosol exposure from a prototypic modified risk tobacco product. Food Chem Toxicol 2015; 80: 328-345.

Motz GT, Eppert BL, Wesselkamper SC, et al. Chronic cigarette smoke exposure generates pathogenic T cells capable of driving COPD-like disease in Rag2-/- mice. Am J Respir Crit Care Med 2010; 181: 1223-1233.

Reidel B, Radicioni G, Clapp PW, et al. E-cigarette use causes a unique innate immune response in the lung, involving increased neutrophilic activation and altered mucin secretion. Am J Respir Crit Care Med 2018; 197: 492-501.

Ghosh A, Coakley RD, Ghio AJ, et al. Chronic e-cigarette use increases neutrophil elastase and matrix metalloprotease levels in the lung. Am J Respir Crit Care Med 2019; 200: 1392-1401.

Garcia-Arcos I, Geraghty P, Baumlin N, et al. Chronic electronic cigarette exposure in mice induces features of COPD in a nicotine-dependent manner. Thorax 2016; 71: 1119-1129.

Korukonda A, Zhang C, Rodriguez L, et al. Electronic cigarettes enhance replication of Mycobacterium abscessus in airway epithelial cells. Am J Respir Cell Mol Biol 2019; 60: 717-719.

Wu Q, Jiang D, Minor $\mathrm{M}$, et al. Electronic cigarette liquid increases inflammation and virus infection in primary human airway epithelial cells. PLOS ONE 2014; 9: e108342.

Higham A, Bostock D, Booth G, et al. The effect of electronic cigarette and tobacco smoke exposure on COPD bronchial epithelial cell inflammatory responses. Int J Chron Obstruct Pulmon Dis 2018; 13: 989-1000. Crotty Alexander LE, Drummond CA, Hepokoski M, et al. Chronic inhalation of e-cigarette vapor containing nicotine disrupts airway barrier function and induces systemic inflammation and multiorgan fibrosis in mice. Am J Physiol Regul Integr Comp Physiol 2018; 314: R834-R847. 
Scott A, Lugg ST, Aldridge K, et al. Pro-inflammatory effects of e-cigarette vapour condensate on human alveolar macrophages. Thorax 2018; 73: 1161-1169.

Higham A, Rattray NJW, Dewhurst JA, et al. Electronic cigarette exposure triggers neutrophil inflammatory responses. Respir Res 2016; 17: 56.

Crosby LM, Waters CM. Epithelial repair mechanisms in the lung. Am J Physiol Lung Cell Mol Physiol 2010; 298: L715-L731.

Stapels DA, Geisbrecht BV, Rooijakkers SH. Neutrophil serine proteases in antibacterial defense. Curr Opin Microbiol 2015; 23: 42-48.

Shapiro SD. Proteolysis in the lung. Eur Respir J 2003; 22: Suppl. 44, 30s-32s.

Stockley RA. Neutrophils and protease/antiprotease imbalance. Am J Respir Crit Care Med 1999; 160: S49-S52. Crisford H, Sapey E, Stockley RA. Proteinase 3; a potential target in chronic obstructive pulmonary disease and other chronic inflammatory diseases. Respir Res 2018; 19: 180.

Kristensen JH, Karsdal MA, Sand JM, et al. Serological assessment of neutrophil elastase activity on elastin during lung ECM remodeling. BMC Pulm Med 2015; 15: 53.

Ostridge K, Williams N, Kim V, et al. Relationship between pulmonary matrix metalloproteinases and quantitative CT markers of small airways disease and emphysema in COPD. Thorax 2016; 71: 126-132.

Johnson SR. Untangling the protease web in COPD: metalloproteinases in the silent zone. Thorax 2016; 71 105-106.

Lee H-W, Park S-H, Weng M-W, et al. E-cigarette smoke damages DNA and reduces repair activity in mouse lung, heart, and bladder as well as in human lung and bladder cells. Proc Natl Acad Sci U S A 2018; 115: E1560-E1569.

Hecht SS. Tobacco carcinogens, their biomarkers and tobacco-induced cancer. Nat Rev Cancer 2003; 3: 733-744.

Kirkham PA, Barnes PJ. Oxidative stress in COPD. Chest 2013; 144: 266-273.

Cross CE, van der Vliet A, O'Neill CA, et al. Oxidants, antioxidants, and respiratory tract lining fluids. Environ Health Perspect 1994; 102: Suppl. 10, 185-191.

Wiegman $\mathrm{CH}$, Michaeloudes $\mathrm{C}$, Haji G, et al. Oxidative stress-induced mitochondrial dysfunction drives inflammation and airway smooth muscle remodeling in patients with chronic obstructive pulmonary disease. J Allergy Clin Immunol 2015; 136: 769-780.

Vénéreau E, Ceriotti C, Bianchi ME. DAMPs from cell death to new life. Front Immunol 2015; 6: 422.

Serpa GL, Renton ND, Lee N, et al. ENDS Aerosol-induced cell death and dysfunction in macrophages and lung epithelial cells. Am J Respir Cell Mol Biol 2020; 63: 306-316.

Wang $\mathrm{H}$, Yu M, Ochani M, et al. Nicotinic acetylcholine receptor alpha7 subunit is an essential regulator of inflammation. Nature 2003; 421: 384-388.

Di Stefano A, Caramori G, Oates T, et al. Increased expression of nuclear factor-kappaB in bronchial biopsies from smokers and patients with COPD. Eur Respir J 2002; 20: 556-563.

Miles PR, Ma JY, Bowman L. Degradation of pulmonary surfactant disaturated phosphatidylcholines by alveolar macrophages. J Appl Physiol (1985)1988; 64: 2474-2481.

Griese M. Pulmonary surfactant in health and human lung diseases: state of the art. Eur Respir J 1999; 13 1455-1476.

Layden JE, Ghinai I, Pray I, et al. Pulmonary illness related to e-cigarette use in Illinois and Wisconsin - final report. N Engl J Med 2020; 382: 903-916.

Maddock SD, Cirulis MM, Callahan SJ, et al. Pulmonary lipid-laden macrophages and vaping. N Engl J Med 2019; 381: 1488-1489.

Blount BC, Karwowski MP, Morel-Espinosa M, et al. Evaluation of bronchoalveolar lavage fluid from patients in an outbreak of e-cigarette, or vaping, product use-associated lung injury - 10 States, August-October 2019. MMWR Morb Mortal Wkly Rep 2019; 68: 1040-1041.

Blount BC, Karwowski MP, Shields PG, et al. Vitamin E acetate in bronchoalveolar-lavage fluid associated with EVALI. N Engl J Med 2020; 382: 697-705.

Bhat TA, Kalathil SG, Bogner PN, et al. An animal model of inhaled vitamin E acetate and EVALI-like lung injury. N Engl J Med 2020; 382: 1175-1177.

Matsumoto S, Fang X, Traber MG, et al. Dose-dependent pulmonary toxicity of aerosolized vitamin E acetate. Am J Respir Cell Mol Biol 2020; 63: 748-757.

Ghosh A, Ahmad S, Coakley RD, et al. Lipid-laden macrophages are not unique to patients with e-cigarette or vaping product use-associated lung injury. Am J Respir Crit Care Med 2020; 203: 1030-1033.

Chen H, Li Z, Dong L, et al. Lipid metabolism in chronic obstructive pulmonary disease. Int J Chron Obstruct Pulmon Dis 2019; 14: 1009-1018.

Romero F, Shah D, Duong M, et al. A pneumocyte-macrophage paracrine lipid axis drives the lung toward fibrosis. Am J Respir Cell Mol Biol 2015; 53: 74-86.

Zhao YD, Yin L, Archer S, et al. Metabolic heterogeneity of idiopathic pulmonary fibrosis: a metabolomic study. BMJ Open Respir Res 2017; 4: e000183. 
Agudelo CW, Samaha G, Garcia-Arcos I. Alveolar lipids in pulmonary disease. A review. Lipids Health Dis 2020; 19: 122.

92 Lawrence $\mathrm{H}$, Hunter A, Murray R, et al. Cigarette smoking and the occurrence of influenza - systematic review. J Infect 2019; 79: 401-406.

93 Lugade AA, Bogner PN, Thatcher $\mathrm{TH}$, et al. Cigarette smoke exposure exacerbates lung inflammation and compromises immunity to bacterial infection. J Immunol 2014; 192: 5226-5235.

94 Baskaran V, Murray RL, Hunter A, et al. Effect of tobacco smoking on the risk of developing community acquired pneumonia: A systematic review and meta-analysis. PLOS ONE 2019; 14: e0220204.

95 Gilpin DF, McGown K-A, Gallagher K, et al. Electronic cigarette vapour increases virulence and inflammatory potential of respiratory pathogens. Respir Res 2019; 20: 267.

96 McEachern EK, Hwang JH, Sladewski KM, et al. Analysis of the effects of cigarette smoke on staphylococcal virulence phenotypes. Infect Immun 2015; 83: 2443-2452.

97 Kulkarni R, Antala S, Wang A, et al. Cigarette smoke increases Staphylococcus aureus biofilm formation via oxidative stress. Infect Immun 2012; 80: 3804-3811.

98 Fahy JV, Dickey BF. Airway mucus function and dysfunction. N Engl J Med 2010; 363: $2233-2347$.

99 Ghosh A, Coakley RC, Mascenik T, et al. Chronic e-cigarette exposure alters the human bronchial epithelial proteome. Am J Respir Crit Care Med 2018; 198: 67-76.

100 Chung S, Baumlin N, Dennis JS, et al. Electronic cigarette vapor with nicotine causes airway mucociliary dysfunction preferentially via TRPA1 receptors. Am J Respir Crit Care Med 2019; 200: 1134-1145.

101 Caramori G, Casolari P, Di Gregorio C, et al. MUC5AC expression is increased in bronchial submucosal glands of stable COPD patients. Histopathology 2009; 55: 321-331.

102 Rebuli ME, Glista-Baker E, Hoffman JR, et al. Electronic-cigarette use alters nasal mucosal immune response to live-attenuated influenza virus. A clinical trial. Am J Respir Cell Mol Biol 2020; 64: 126-137.

103 Herr C, Tsitouras K, Niederstraßer J, et al. Cigarette smoke and electronic cigarettes differentially activate bronchial epithelial cells. Respir Res 2020; 21: 67.

104 Gómez A-C, Rodríguez-Fernández P, Villar-Hernández R, et al. E-cigarettes: effects in phagocytosis and cytokines response against Mycobacterium tuberculosis. PLoS ONE 2020; 15: e0228919.

105 Corriden R, Moshensky A, Bojanowski CM, et al. E-cigarette use increases susceptibility to bacterial infection by impairment of human neutrophil chemotaxis, phagocytosis, and NET formation. Am J Physiol Cell Physiol 2020; 318: C205-C214.

106 Soler-Cataluña JJ, Martínez-García MA, Román Sánchez P, et al. Severe acute exacerbations and mortality in patients with chronic obstructive pulmonary disease. Thorax 2005; 60: 925-931. 